\title{
Sociodemographic characteristics and identified needs among patients followed in palliative care units in the Republic of Benin
}

\begin{abstract}
Introduction: In Benin, the experience of palliative care began in 2014 with an approach based on the model of Hospice Africa Uganda. Patients usually come to the hospital at a fairly advanced stage and require a full support, taking into account their need. This observation justifies the study whose objectives were to describe the sociodemographic characteristics of patients in palliative care and to identify their needs.

Methods: This is a descriptive and retrospective cross-sectional study conducted from 1st December 2014 to 31 st July 2016. It concerned all patients followed in palliative care units of the CNHU HKM and Comè District Hospital and who have a complete medical record.

Results: Sixty-five (65) patients were followed in the palliative care units during the study period. Among them women were $61.5 \%$ with a sex ratio of 0.6 . They mean age was 52.85 years. $78 \%$ of patients did not have social security coverage. $89.2 \%$ of patients admitted to palliative care units had cancer and $63.79 \%$ were already in the metastatic stage. Pain was present in all patients admitted to palliative care units. Other problems identified were spiritual support $(90.2 \%)$ and psycho-social support $(73 \%)$.

Conclusion: Palliative patient's needs in Benin are dominated by pain control and psychosocial and spiritual support. A palliative care program focused on these needs will provide a better quality of life for these patients.
\end{abstract}

Keywords: palliative care, needs, Benin
Volume 3 Issue 2 - 2019

\author{
Agbodande KA,' Prudencio RDTK,' \\ Gnintoungbe $S$,' Sowanou AKV, ${ }^{2}$ Ayosso \\ $M,{ }^{\prime}$ Fandi $O,{ }^{2}$ Gnangnon F,' Aguegue A,' \\ Hounsa A,' Kouassi Zannou L, ${ }^{3}$ Djossou G, ${ }^{3}$ \\ Watchinou FV,' Sehonou J, ${ }^{3}$ Zannou DM,' \\ Ezin-Houngbe $\mathrm{J}^{3}$ Houngbe $\mathrm{F}^{\mathrm{I}}$ \\ 'Palliative Care Unit of Hubert Koutoukou Maga Teaching \\ Hospital, Benin \\ ${ }^{2}$ Palliative Care Unit of the Comè District Hospital, Benin \\ ${ }^{3}$ Beninese Association for Palliative Care (ABSP), Benin
}

Correspondence: Agbodande Kouessi Anthelme, Palliative care unit of Hubert Koutoukou Maga Teaching Hospital, Benin, Tel+2296470I209, Email agbotem@yahoo.fr

Received: January 31, 2018 | Published: March 08, 2019

\section{Introduction}

Comprehensive care of patients requires the collaboration of all members of a health care team. This support can be as well preventive, curative as palliative especially for end of life patients. ${ }^{1}$ According to this approach, the patient is considered a living being and death as a natural process. ${ }^{2}$ In Africa, where the majority of deaths occur at home, the experience of palliative care developed by the Hospice Africa Uganda Foundation (HAU) remains unprecedented. In Frenchspeaking Africa, palliative care is poorly known and not integrated into the national health system. ${ }^{3}$

In Benin, the experience of palliative care began in 2014 with an approach based on the model of Hospice Africa Uganda. Benin is a country in West Africa, with a general population of about 10 million people. ${ }^{4}$ The infant mortality rate is 54.2 deaths/1,000 normal births and, according to World Bank data, poverty remains widespread $(40.1 \%)$ due to low per capita growth rates. ${ }^{5}$ Benin's health profile is characterized by a predominance of communicable diseases and the emergence of non-communicable diseases in recent years. Noncommunicable diseases, particularly cancers, are a real public health problem in Benin. Cancers are dominated by breast and cervix cancers in women and prostate cancer in men. ${ }^{6}$

Cancer patients generally go to hospital at a fairly advanced stage of the disease and often require palliative care that must take into account their physical, psychosocial and spiritual needs. This observation justifies the study whose objectives were to describe the socio-demographic characteristics of patients in palliative care and to identify their needs.

\section{Material and methods}

This is a descriptive and retrospective cross-sectional study conducted from 1st December 2014 to 31st July 2016. It concerned all patients followed in palliative care units of the CNHU HKM and Comè District Hospital and who have a complete medical record. The data were collected using a survey sheet concerning the socio-demographic profile of the patients, their spiritual, clinical and psychological profile as well as the terms of their care. These data were then coded, saved and analyzed by SpSS software version 18.0. The description of the sample was made according to the usual statistics (frequency, average, standard deviation).

\section{Results}

\section{Sociodemographic characteristics of the population}

Sixty-five (65) patients were followed in the palliative care units during the study period. Among them women were $61.5 \%$ with a sex ratio of 0.6 . The mean age was 52.85 years with extremes ranging from 16 to 82 years. The majority of patients $(63 \%)$ lived in couple. More than $3 / 4$ of the patients $(78 \%)$ did not have social security coverage and the patients were mostly of a very low socioeconomic level $(70 \%) .83 \%$ of patients had a close relationship with their caregivers. Almost all patients (98\%) reported having a strong belief in God and were mostly Catholic (56\%). The rest was evangelist (16\%), celestial Christianity (6\%), Islamist $(9 \%)$ or endogenous religions $(13 \%)$. Almost all patients (95\%) said they used prayer, expressed their effectiveness. They also said they were mostly at peace with God (98\%). 


\section{The clinical characteristics of the study population}

All patients required pain control (100\%). 25\% were referred for psychological support while $20 \%$ were followed for end-of-life care. $89.2 \%$ of patients admitted to palliative care had cancer and $63.79 \%$ of the cancers were already in the metastatic stage. Breast cancer was predominant at $22.41 \%$ (Table 1 ).

Table I Distribution of cancer patients according to the original site

\begin{tabular}{lll} 
& Number $\mathbf{N}=\mathbf{5 8}$ & $\mathbf{\%}$ \\
\hline Breast cancer & 13 & 22.41 \\
Leukemia & 7 & 12.07 \\
Uterus cancer & 6 & 10.34 \\
Pancreatic cancer & 6 & 10.34 \\
Stomach cancer & 4 & 6.90 \\
Colon/rectal cancer & 4 & 6.90 \\
Bronchial cancer & 3 & 5.17 \\
Vaginal cancer & 2 & 3.45 \\
Prostate cancer & 2 & 3.45 \\
Ovarian cancer & 2 & 3.45 \\
Myeloma & 2 & 3.45 \\
Other* & 7 & 12.07 \\
\hline
\end{tabular}

Other*: cancer, anus, vulva, bone, skin, clavicle, ear, duodenum

Pain is observed in all patients receiving palliative care. The other most common symptoms were asthenia, nausea, vomiting and constipation. Table 2 shows the distribution of patients according to the main symptoms observed.

Table 2 Distribution of patients according to symptoms observed

\begin{tabular}{lll}
\hline & Number $(\mathbf{n}=\mathbf{6 5})$ & $\mathbf{\%}$ \\
\hline Pains & 65 & 100.0 \\
Asthenia & 13 & 20.0 \\
Nausea and vomiting & 8 & 12.3 \\
Constipation & 8 & 12.3 \\
Anorexia & 6 & 9.2 \\
Cough & 6 & 9.2 \\
Mouthwashes, dysphagia & 6 & 9.2 \\
Anxiety and depression & 5 & 7.7 \\
Dyspnea & 4 & 6.2 \\
Bedsores and wounds & 4 & 6.2 \\
\hline
\end{tabular}

All patients have at least one pain site. $46.2 \%$ have two sites. About $62 \%$ of patients have severe pain ( 4 or 5 EVS). Nearly $66 \%$ of patients said that pain affects their sleep and mobility. Moreover, for $66 \%$ of patients, the usual analgesics used have only partially controlled the pain. The main sites of these pains are the thorax (35.4\%), the abdomen (26.1\%) and the breasts (18.5\%). Half of the patients (52\%) were treated with morphine (Figure 1). Pain relief was the basic need of all patients (Figure 2).

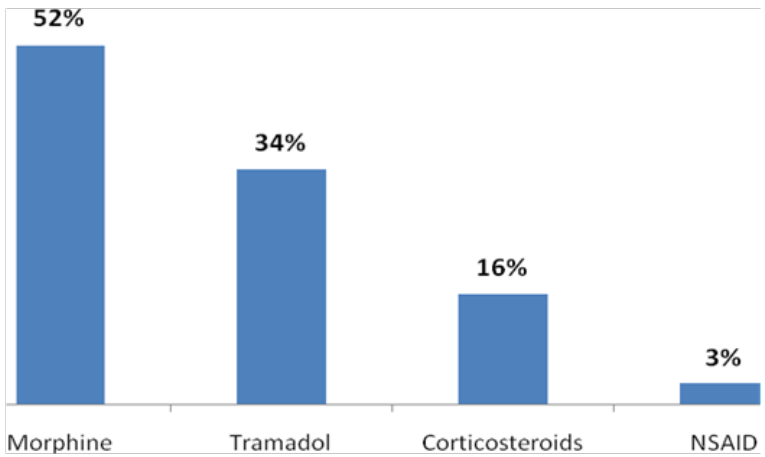

Figure I Distribution of patients according to the analgesics used.

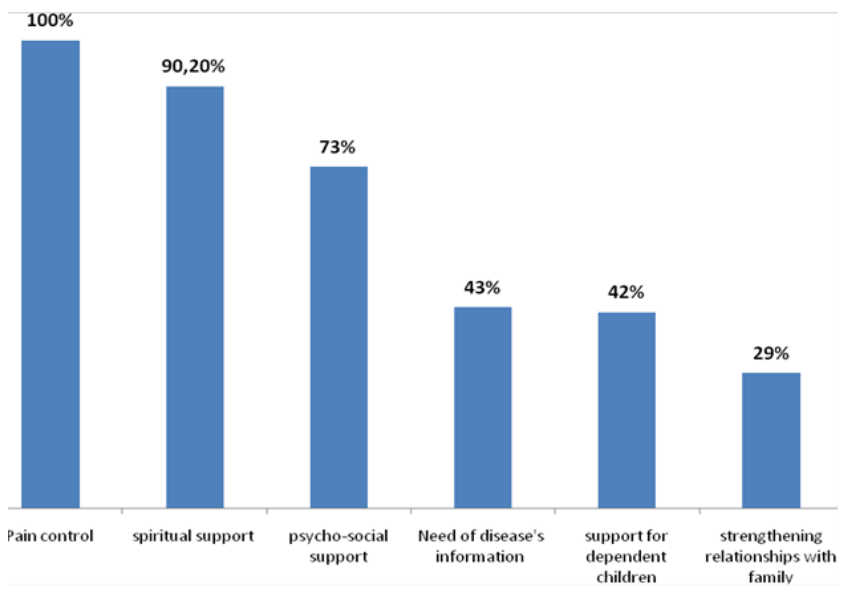

Figure 2 Distribution of patients according to the needs expressed.

\section{Discussion}

The majority of patients, $61.5 \%$ included, were female. This result is similar to Obtel $\mathrm{M}$ et al. ${ }^{7}$ who found that $66.5 \%$ of patients in Morocco's oncology institutions are female. Women's cancers were the most common in our study. According to Selman et al. ${ }^{8}$ in their study of palliative care patients quality of life in South Africa and Uganda, patients are also predominantly female (69.1\%).These results reflect the first rank of cancer in women. In Africa and developing countries, cervical cancer and breast cancer are the first two predominant cancers. ${ }^{69}$ Most of our patients do not have health insurance. In fact, in sub-Saharan Africa, as Richard $\mathrm{V}^{10}$ noted, cost recovery still poses the problem of financial accessibility through the absence of a risk-sharing policy coupled with geographical accessibility through a lack of monitoring of health coverage. ${ }^{10}$ These results do not deviate from those recorded by Bachisse IIham ${ }^{11}$ who reported that $63.3 \%$ of the surveyed population do not have health insurance. This contrasts with the care needs of these patients. Since the disease usually has a disabling effect on patients, health insurance proves to be an indispensable social measure for patients who receive palliative care. The absence of health insurance as pointed out by King $\mathrm{M}$ et al. ${ }^{12}$ in his study, is also a factor of dissatisfaction of the patients. The majority of the patients is $70,8 \%$ being of a low socioeconomic level (patients of score 3, $4 \& 5$ ), they need the third party support to improve their quality of life. The lack of material means and the lack of purchasing power are factors aggravating their situation. This confirms the findings of Wenk Roberto ${ }^{13}$ who, in his study of cancer progression in Argentina, has shown that more than 50\% of patients are unable to pay for care and medication themselves. 
All palliative care patients emphasized that pain is the main symptom. This result is comparable to that of Sepulveda C et al. ${ }^{14}$ who found that in most African countries, pain is the main symptom among patients followed in palliative care units. This is also consistent with the findings contained in Audrey Hardy's ${ }^{15}$ end-of-study thesis at IFSI, which stated that "pain is the most common symptom in palliative care". This result is significantly different from the $38 \%$ reported by Bouté $\mathrm{C}$ et al ${ }^{16}$ in their study on the estimation of palliative care needs in short-stay institutions in Dijon, France. The present study showed that analgesics used to calm patients' pain before admission to palliative care units resulted in total pain control in only $30.7 \%$ of cases. This result is below the standards set by the WHO for treating cancer pain; these standards aim for affordable and adequate relief in $70 \%$ to $80 \%$ of patients with cancer pain. ${ }^{17}$ The same observation is made by Boute $\mathrm{C}^{16}$ and al who reported that the analgesics used are not satisfactory in more than $25 \%$ of the cases involved.

The needs related to pain control, spiritual assistance and psychosocial support are the most serious concerns expressed by palliative care patients in the visited units.

The majority of palliative care patients, $90.2 \%$, reported that they needed spiritual support. This result is consistent with findings from another study in a palliative care unit in Hong Kong. Among the conditions that affected the quality of life the most were the recognition of personal existence, the achievement of important life goals, the value of life, and self-esteem. It was also the most difficult area to maintain until the last days, representing a challenge for carers. ${ }^{17}$ In addition, the result is consistent with that obtained by Shaiova $\mathrm{L}^{18}$ who states that in the extreme, the "spiritual" suffering was the reason for sedation at the end of life and is part of the very exceptional conditions of this indication. In the same way, the French Society of Assistance and Palliative Care states that another extreme is the justification of the demand for euthanasia by a "spiritual" need to preserve the control of one's life. ${ }^{19}$ However, our results are against the findings of Ekiria Kikule ${ }^{20}$ in Uganda who reported in her sturdy that less than $1 \%$ of patients expressed a spiritual need. This study is limited in that it examined the patients' needs at the time of the study but does not indicate whether these needs changed as death approached. Ndiok ${ }^{21}$ however, reported an important place of spiritual need among cancer patients followed in palliative care in Nigeria.

Nearly three quarters of patients in palliative care or $73 \%$ expressed the psychosocial support as an important need. This result is consistent with those previously obtained from the research of Too et al. ${ }^{22}$ "Emotional anxiety and mental health problems in cancer patients can come from substantial social problems, such as the inability to work and reduced income, lack of insurance, and lack of support". ${ }^{22}$ The same observation is made with regard to the results of the Van Der Plas et al. ${ }^{23}$ statistical study, which indicates that only $8 \%$ of patients have their full mobility. The $92 \%$ must rely on the help of parents, children or friends. This shows that dependence is the result of all symptoms in palliative care and that family support is a major advantage in the provision of palliative care.

\section{Conclusion}

Patients admitted to palliative care in Benin are mostly cancer patients and are in a precarious social situation. Their needs are dominated by pain control and psychosocial and spiritual support. A palliative care program focused on these needs will provide a better quality of life for these patients.

\section{Acknowledgments}

None.

\section{Conflicts of interest}

The authors declare there is no conflict of interest.

\section{References}

1. Aubry R. Current situation of palliative care development in France in 2010. Paris: National Committee for the Follow-up of Palliative Care Development; 2011.

2. National Agency for Support and Assessment in Health (ANAES): Recommendation for Clinical Practice. Modality of care of the adult requiring palliative care. Paris: ANAES, 2002.

3. Ikrou A. Care for end-of-life patients by nurses: Case of the national institute of oncology sidi Mohamed ben Abdallah of Rabat, Master thesis for the diploma of paramedical studies of $2^{\text {nd }}$ cycle). Rabat; 2008:72.

4. https://www.insae-bj.org/statistiques/enquetes-et-recensements

5. http://www.banquemondiale.org/fr/country/benin/overview

6. Egue M, Gnangnon FHR, Akele-Akpo MT, et al. Cancer incidence in Cotonou (Benin), 2014-2016 First results from the cancer Registry of Cotonou. Cancer Epidemiology. 2019;59:46-50.

7. Obtel M, El Achhab Y, Bendahhou K, et al. Patient satisfaction in Moroccan oncology and satisfaction in Moroccan patient with cancer. African Journal of Cancer. 2012;4(1):9-17.

8. Selman L, Higginson J, Agupio G, et al. Quality of life among patients receiving palliative care in South Africa and Uganda: a multi - centered study. Health Qual Life Outcomes. 2011;10:9-21.

9. World Health Organization. World Health Report: Overcoming Suffering Enriching Humanity. Geneva (Switzerland) 1997:23-43.

10. Richard V. Le financement de la santé en Afrique sub-saharienne le recouvrement des coûts. Med Trop. 2004;64:337-340.

11. Bachisse I. Measurement of the satisfaction of the users of the palliative care unit/treatment of pain/emergencies, final dissertation. Rabat; 2012:58.

12. King M, Llewellyn H, Leurent B, et al. Spiritual beliefs near the end of life: a prospective cohort of people with cancer receiving palliative care. Psycho-Oncology. 2013;22(11):2505-2512.

13. Wenk R. Cancer pain-progress and ongoing issues in Argentina. Bread Res Manag. 2009;14(5):350-351.

14. Sepulveda C, Habiyambere V, Amandua J, et al. Quality care at the end of life in Africa. BMJ. 2003;327(7408):209-213.

15. Hardy Audrey. The psychological dimension of the end of life. Thesis Henri Mondor Nursing Education Institute; 2012:53.

16. Bout C, Millot I, Ferré P, et al. How to estimate palliative care needs in short-stay facilities in Dijon, France. Public Health. 1999;11(1):29-39.

17. Lo RS, Woo J, Zhoc $\mathrm{KCH}$, et al. Quality of life of palliative care patients in the age of two weeks of life. J Pain Symptom Manage. 2002;24(4):388-397.

18. Shaiova L. Case presentation: "terminal sedation" and existential distress. J Pain Symptom Manage. 1998;16(6):403-404.

19. French Society for Assistance and Palliative Care (SFAP). Sedation for terminal distress and in specific and complex situations. Recommendations of the French Society of Assistance and Palliative Care. Paris: SFAP; 2010. 
20. Kikule E. A good death in Uganda: survey of needs for palliative care for terminally ill people in urban areas. BMJ. 2003;327(7408):192-194.

21. Ndiok A, Ncama B. Assessment of palliative care needs of patients/ families living with cancer in a developing country. Scand J Caring Sci. 2018;32(3):1215-1226.
22. Too W, Watson M, Harding R, et al. Living with AIDS in Uganda: A Qualitative Study of Patients 'and Families' Experiences Following Referral to Hospice. BMC Palliative Care. 2015;14:1-7.

23. Van der Plas GM, Francke AL, Vissers KC, et al. Case management in primary palliative care is more strongly associated with a crosssectional prospective study. BMC Palliat Care. 2015;29(8):1-10. 